\title{
EXTENDED REALITIES AS METHODS OF REPRESENTATION WITHIN ARCHITECTURAL PEDAGOGY
}

\author{
Tatiana Estrina ${ }^{1 *}$, Vincent $\mathrm{Hui}^{2}$ \\ ${ }^{1}$ Mrs., Ryerson University, Canada, testrina@ryerson.ca \\ 2Prof, Ryerson University, Canada, vincent.hui@ryerson.ca \\ ${ }^{*}$ Corresponding Author
}

\begin{abstract}
Although various extended reality (XR) technologies share origins in entertainment, the medium has warranted integration within a range of disciplines, most notably in architectural praxis and pedagogy. In the past, immersive technologies have become synonymous with architectural representation. Previously, XR tools were confined to the visualization of final outcomes, however with increasingly robust software and hardware, they have begun to cascade into other developmental processes and phases. In recent years, there has been a strong push in academia to incorporate immersive experiences into development and idea iteration processes, representation methods, and media for instruction. Such tools are not only able to improve architecture student's abilities to understand the spaces they design digitally in a more comprehensive manner but they are also able to provide extensive insight into existing and historical architectural projects, allowing students to gain a more complete understanding of the built environment.

This paper re-examines the AEC industry's relationship with various immersive media and the role these XR technologies play within architectural development and processes. It will begin with defining and distinguishing various $X R$ technologies, including virtual reality (VR), augmented reality (AR) and mixed reality (MR), through a literature review. Through a series of case studies within both architectural pedagogy at Canada's largest architecture program and the professional industry at large, this paper will posit not only the changes in the purpose of immersive technologies in architecture, but also outline the merits for their use within contemporary architectural pedagogy. The paper concludes with projections on the future role of XR platforms within the context of architectural pedagogy.
\end{abstract}

Keywords: Pedagogy, experiential learning, extended realities, virtual reality, augmented reality.

\section{INTRODUCTION}

As architects serve as the designers of the built world, rather than the craftsmen, architectural praxis revolves primarily around representation of $3 \mathrm{D}$ environments and objects in order to communicate intention and ideas. From the development of $2 \mathrm{D}$ representation in the form of drawings and perspectival representation in renderings through to physical modeling, architects have always been tasked with discovering the most comprehensive methods of representation. With the technological boom in the late $20^{\text {th }}$ century, the industry was able to transition from hand drawing and model making to computer aided design (CAD) software and subsequently building information modeling (BIM). Such innovations allowed for architects to generate 3D digital representations of their ideas and subsequently use those to create additional imagery.

Most recently, through the integration of rendering and gaming engines into the workflow, the emerging technologies of XRs, including VR, AR, MR, were able to be integrated into architectural praxis. These 
technologies allow for digitally generated 3D models to exist at a 1:1 scale around the view, giving them previously unimaginable vantage points and capabilities. Architectural pedagogy is composed primarily of two components, design education and lecture-based instruction. This presentation/paper will first define the three main technologies within the extended reality umbrella, before examining the current implementation of these technologies within architectural curricula. Within the context of architectural pedagogy there are two main streams of application for extended realities within the context of design development and process in studio in design studio classes in the context of presentation and finally within the context of instruction.

\section{XR PLATFORM TYPOLOGIES}

According to the taxonomy developed by Milgram and Colquhoum, XRs fall onto a reality-Virtuality spectrum, that describe how 'real' or 'virtual' the technology is. This stratification is defined by four distinct levels, real presence, augmented virtuality, augmented reality, and pure virtual presence (1999). Where virtual presence becomes the inhabitation of an entirely virtual environment, augmented reality refers to a digital superimposition onto physical space, augmented virtuality because a superimposed digital onto physical space that is reactive to real world changes, and real presence refers to the user's true surrounding reality without digital interference (Wang, Wu, Wang, Chi, \& Wang 2018).

According to this metric, VR falls onto the virtual presence side of the spectrum. VR entails the visual immersion into a digitally manufactured space through the placement of a headset over the eyes (Hui, Estrina and Huang, et al., 2020). Most frequently, VR is a navigable and interactive digital environment, experienced using VR headsets such as the HTC Vive or Oculus devices. VR can also be delivered in the form of a 360 degree still image or video, where no matter how much the user displaces their vantage point the digital view remains the same. Such imagery is much less demanding in terms of hardware and can be viewed on mobile devices via headsets. Due to the costs of VR headsets, they are often prohibitive for individual students to process, whereas the mobile-based viewing configurations are much more accessible and therefore preferred in architectural pedagogy (Hui, Estrina and Lee, et al., 2020). VR environments serve as an effective way to immerse the viewer in architectural projects, allowing them to gain a greater understanding of the spatial characteristics.
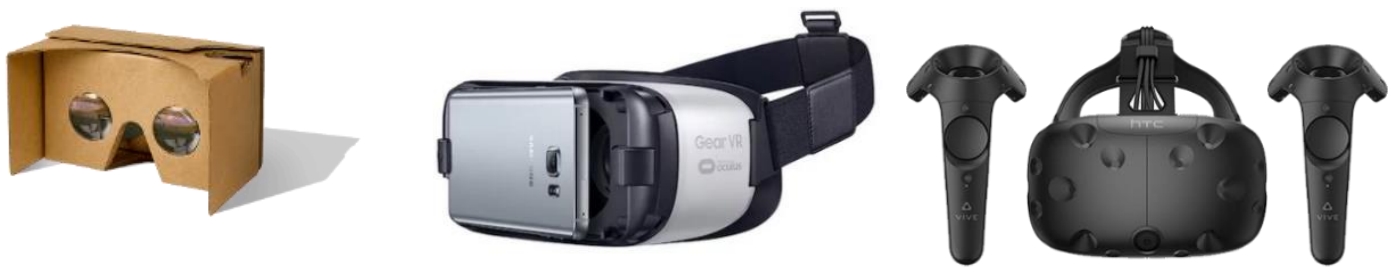

Fig. 1: Three types of available headsets, inexpsnive mobile sets in the Google Cardboard (Left), more advnaced mobile sets in the Gear VR (Center) and the most expensive and technolgoically advanced in HTC Vive (Right) (Hui, Estrina, Lee, Zhou, \& Kinuthia, 2020).

$\mathrm{AR}$ on the other hand, is the superimposition of a digital image or model onto the real environment. These projections do not respond to the surroundings and changing conditions around them, and instead act as independent entities. However, AR projections are able to be attached to glyphs or QR codes, allowing them to be moved and transported through space so that users are able to navigate around the digital projection. Introduced into mainstream culture through the integration into the mobile Pokémon Go game (Paavilainen, et al., 2017), AR is generally viewed via a screen, most often on mobile devices or smart glasses. This technology is most frequently used in the display of objects into an environment, such as the viewing of a digital scale model onto a physical site model or the actual site.

Finally, MR serves as the bridge between the virtual and the physical world. Operated via state-of-the-art headsets such as Microsoft's HoloLens or LeapMotion, MR not only creates holographic overlays overtop of the user's surroundings but also is able to track the user's movements and changes in the physical environment. MR has become a quickly growing technology within the AEC industry at large, used most notably for overlay representation in construction and fabrication.

\section{APPLICATIONS OF XRS IN ARCHITECTURAL PEDAGOGY}

\subsection{Extended Realities within the Context of Lecture-Based Instruction}

In many cases for architectural education, purely visual and verbal communication is insufficient in the holistic understanding of the subject matter, and more engaging interaction is required. Using emerging 
technologies, students can be transported outside of the classroom environment and gain a greater contextual understanding of their course content. In addition, these technologies can be invaluable when leading history and theory courses, where students are usually only shown 2D imagery of the buildings and cities they study.

From technical courses such as construction detailing and structures, to theory and history courses, AR serves as an invaluable tool in teaching within the architectural context (Hui, Duldul, McCarthy, \& Ghantous, 2012). Through the super-imposition of "layers of geo-located data atop real-world displays on mobile devices" students are able to view multimedia content as a "live database of imagery and data on buildings" and able to conduct augmented self-guided explorations of cities. Through the development of the Arch-App, Hui, Townsend, Ghantous, and McCarthy (2013) developed a new platform for the representation of multimedia content overtop the built context in Toronto by making use of student's smartphones cabalitites. Initally taking the form of a database for factual information, such as building's architects and dates of completion, the project then used geo-location in order to more effictivly represent and convay this information to students. Students were not only able to interact with the content on site, but also gain additional insight that may not be accessible to students otherwise (Hui, Townsend, Ghantous, \& and McCarthy, 2013). Such tools can also be applied onto lost architecture, such as ruins or demolished buildings, superimposing lost architecture over the existing urban conditions (Fig. 5). Within the Arch-App, not only can students view additional information such as imagery and video content of the buildings at various time periods, orthographic drawings, and even photographs of past constructions on the site (Hui, Townsend, Ghantous, \& and McCarthy, 2013).
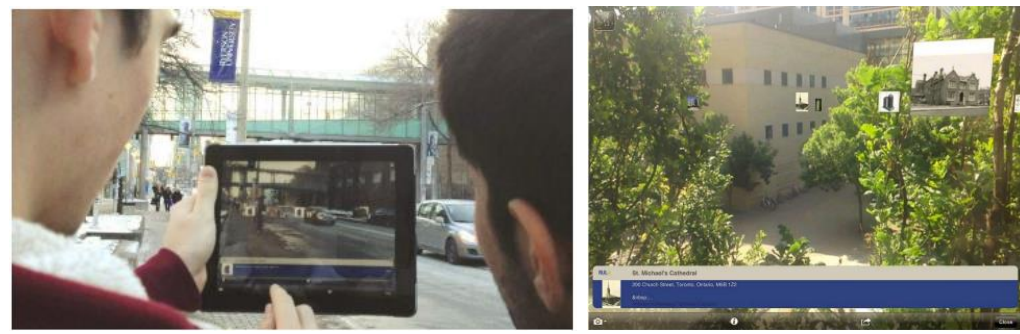

Fig. 5: Arch-App from Ryerson University being used to represent building data using geo-location via mobile devices (Hui, Townsend, Gantous, \& and McCarthy, 2013).

As architecture is a very $3 \mathrm{D}$ medium, it is very difficult for students to entirely understand constructions without physically occupying them, yet travel is not always a feasible option for many (Hui, Estrina, Lee, \& Sarmiento, 2019). Interactive Virtual Field Trips (iVFTs) can harness the benefits of VR and the internet of things in order to provide students with opportunities to travel to architectural sites digitally (Hui, Estrina, Huang, \& Agma, 2020). Where "physically transporting, lodging, and sustaining" students on excursions is not viable, provides a much more cost-effective alternative. Although far-removed from the physical exploration of the premises, using consumer-grade mobile headsets, students are able to view 360 degree still or video representations of the sites. In a study, students were shown to have gained significantly more knowledge in content after having experienced iVFTs (Mead, 2019). Within Ryerson University's Architectural Science program, students are offered the option of participating in short excursions to various cities, and if they are unable to participate physically are given the opportunity to experience the sites virtually in iVFTs (Hui, Estrina, Lee, \& Sarmiento, Advanced Computer Visualization in Architectural Pedagogy, 2019).
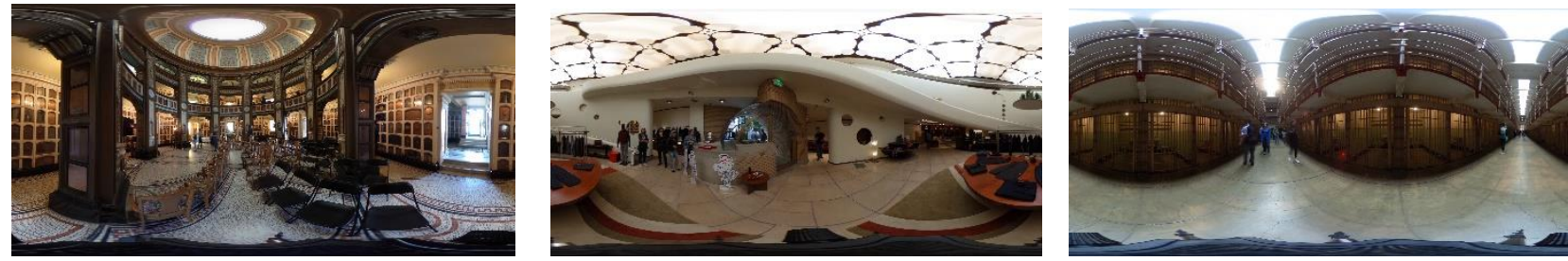

Fig. 6: iVFT locations of San Fransico; Columbarium (left), Xanadu Gallery (center), and Alcatraz (right).

Although iVFTs most frequently take place using imagery of existing conditions, entirely digital environments are viable visitation sites as well. In recent years, a multitude of VR platforms with various "user-generated projects that are designed to enhance the virtual learning environment" have appeared (Dawkins \& Young, 
2020). One such platform is AltSpaceVR, which provides users with free avatar-based occupiable environments, but also the ability to generate customized content. Within the high-fidelity social VR environment, users are given the ability to teleport through the spaces, talk with one another, and communicate with others, augmenting the typical individual iVFT to become a much more realistic, social experience (McVeigh-Schultz, Márquez Segura, Merrill, \& Ibister, 2018). With the aid of AltSpaceVR students are not only able to immerse themselves in locations, but also actively participate in the selection, generation, and interaction with the content (Dawkins \& Young, 2020). The diverse content found on these platforms ranges from existing urban conditions built from in-situ image captures (Dawkins \& Young, 2020), but also lost historical locations, and unbuilt designer projects. Increasingly, architects and designers begun to take advantage of these virtual platforms in order to disseminate their work. Due to the COVID-19 pandemic, the annual Burning Man festival was unable to be held in person. In order to retain the enduring tradition, the community transitioned to the AltSpaceVR platform to virtually re-create Black Rock City (Rowen, 2020). In addition to various dancers and artists who took to virtual means of performance, the architect, Arthur Mamou-Mani, included his pavilion in the immersive environment for visitors to enjoy. Capitalizing on the digital platform, the architect chose to also include two additional pavilions, including the famous Galaxia Temple, from previous Burning Man festivals as they are burned at the end of the event. In this way, architecture students were able to visit now-destroyed structures alongside unbuilt projects. Additionally, the recently launched Illusorr world designed by Oleg Soroko and hosted via Sansar, acts as a meeting place, gallery and platform for designers and architects to display, share, and collaborate on projects.
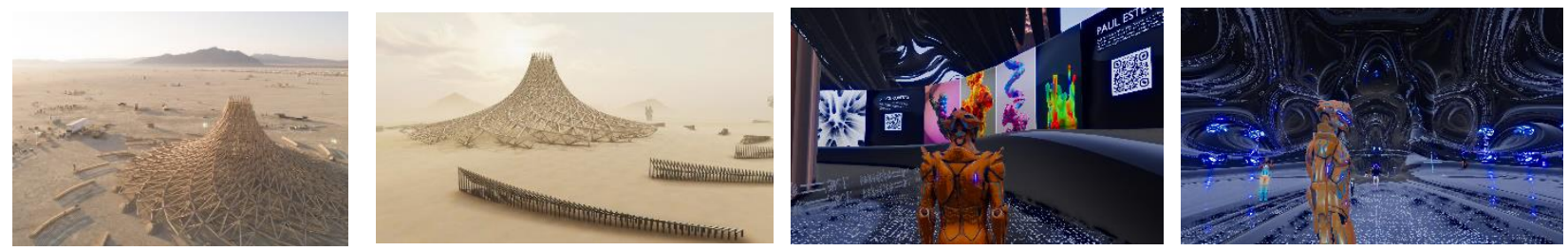

Fig. 7: The Galaxia temple by Arthur Mamou-Mani at the Burning Man Festival (Left) and at the AltSpaceVR Digital Festival (Center) that students were able to explore in VR. On the right, are views of the Illusorr platform and an artist work display.

Through virtual means, students can not only visit these locations virtually via iVFTs and understand the contexts surrounding the architecture but can also better visualize architecture that has now been lost. The Virtual Experience Lab, a research group at MIT, were able to generate a VR experience of Lifta, Jerusalem based on archeological findings (Nagakura, Mann, \& Keller, 2019). The resulting phogramtric models and additional site evidence was on display for the public in order to provide additional content, thereby generating a variety of storylines from various points of view (Nagakura, Mann, \& Keller, 2019). Similarly, William Michael Carter (Carter, 2017) led Ryerson University to collaborate with Seneca College and Humber College in order to generate a cross-disciplinary, inter-institutional project intent on the creation of a virtual experience of a traditional Heron-Wendat longhouse, in response to the Truth and Reconciliation Commission (Truth and Reconcilation Commission of Canada, 2015). This project was intended to allow students to understand the way in which the building was not only constructed but also how it was occupied. This project, involving architecture, video game, animation and sound design students and faculty, not only created a virtual presentation of the project but also multi-sensory enclosure for the user to have various other senses stimulated along with their visual (Hui, Estrina, Lee, \& Sarmiento, 2019). This augmentation presents a precedent for both architects and students in the development of multi-sensory environments (Hui, Estrina, Zhou, \& Lee, 2020).
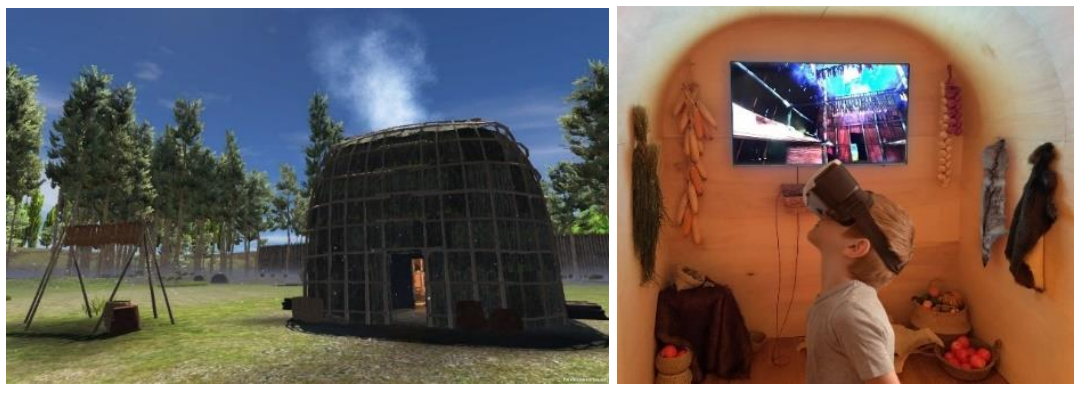

Fig. 8: Archaeology Alive, an award-winning installation at the Whitchurch-Stouffville museum, depicting a Heuron-Wendat Longhouse. 


\subsection{Extended Realities within the Context of Design Instruction}

Within architectural pedagogy, a large focus is placed on the design studio courses, where students are instructed and evaluated on not only their design abilities but also the success of their workflow (Ockman and Williamson, 2012). The uses for extended within initial architectural design development are numerous in enhancing the creative process and the means of communication of ideas, as well the enhancement of analytical tools for developing schematic concepts.

Using various platforms and plug-ins into popular modeling software, students able to create 360 still renderings of their projects very easily and view them almost instantaneously on their mobile devices. This allows students, as early as their first year of studies, to view their projects not only as they appear digitally on screen, but also as though they are occupying the space. This is invaluable for them, especially those in their early years of education, in order to gain a greater understanding of the scale, material assemblies, and spatial qualities of the environments they design. In addition, using more advanced VR headsets students are also able to create fully navigable environments from their 3D models. This allows students to experience the space with live characteristics, such as daylighting, and giving them the ability to examine finer details, for instance the underside of a table.

With these technologies, students are not only able to view their models, but generate them in VR as well. Integrating many of the typical modeling features, MindeskVR is a plugin allowing for the computer interface to be replaced with VR. Such an approach grants the modeler freedom from constants set upon them by viewports and trackpads and makes the 3D modeling process a lot more involved, intuitive, and personal. Such modeling methods mimic closely the experience of physical modelmaking, as all the changes and edits are made with one's hands. In addition, such software allows for a much more fluid collaboration between students, where multiple students are able to edit and add components via the computer or VR interfaces simultaneously.
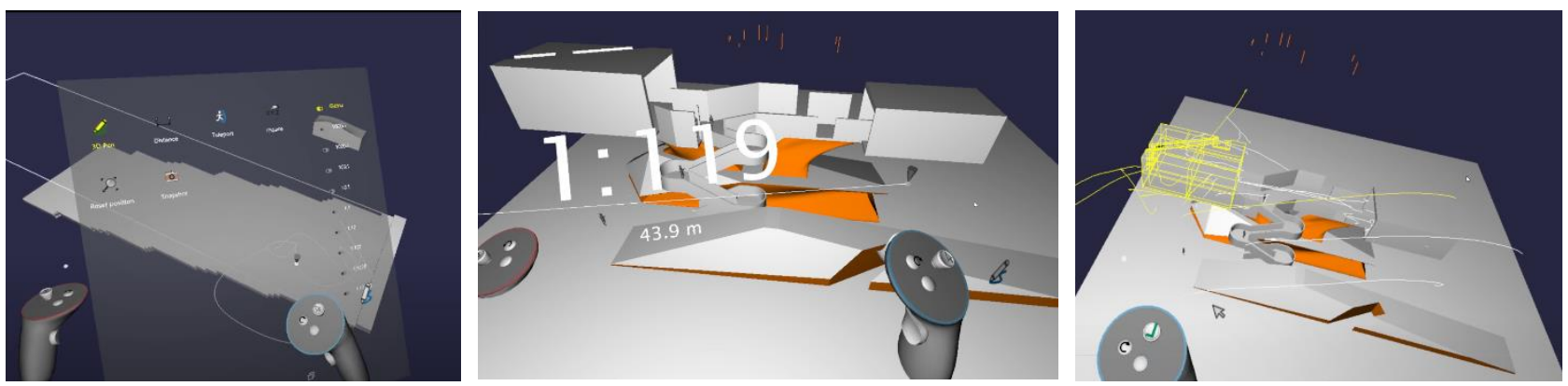

Fig. 2: Plug-ins such as MindeskVR allow for students to digitally model in VR, creating a much more handson and interactive experience (Hui, Estrina, Huang, \& Algma, 2020).

An understanding of how designs play into a larger site and the contextual influences of a building's location are very important for students to consider in their interactive design processes. AR- based hybrid iterative processes including the $A R$ Workbench (Ishii, et al., 2002) and ARTHUR (Broll, et al., 2004), have been experimented with to allow for the augmentation and manipulation or digital models overtop physical conditions (Megahed, 2013). These methods were intended to give a two-fold advantage to students, the ability to view larger portions of urban conditions and visualize "previously intangible factors such as wind speed, shadow movement and traffic flow" while retaining the ability to communicate verbally and visually with peers and faculty (Ishii, et al., 2002). In addition, the ARTHUR platform gave users the ability to take part in the simulations and generation of the model using gestural cues (Broll, et al., 2004). The Augmented Reality in Design Development (ARIDD) Project (Fig. 3) was initiated at Ryerson University, in order to "bridge the disconnect between design ideation and application in real work and real time" (Hui, Compeau, $\mathrm{Pu}$, \& Arabian, Design in Hand | A Pedagogical Application of Augmented Reality in Design Development, 2013). This platform harnesses the technology from the entertainment industry in order for students to be able to view their design iterations and evaluate their contextual suitability, while being able to rabidly and make changes in the AR environment (Hui, Compeau, Pu, \& Arabian, Design in Hand I A Pedagogical Application of Augmented Reality in Design Development, 2013). The models can be used as superimpositions onto various media, from scaled physical site models to real-world conditions (Hui, Compeau, Pu, \& Arabian, Eliminating Virtual Barriers | Augmented Reality in Architectural Design through Arch-Viz, 2013). AR technologies give students the abilities to rapidly visualize their project designs within site contexts, both at a scale and on site itself and as such, a such more time and cost-efficient alternative to physical model-making, as digital models are easily modifiable (Zarzycki, n.d.). 

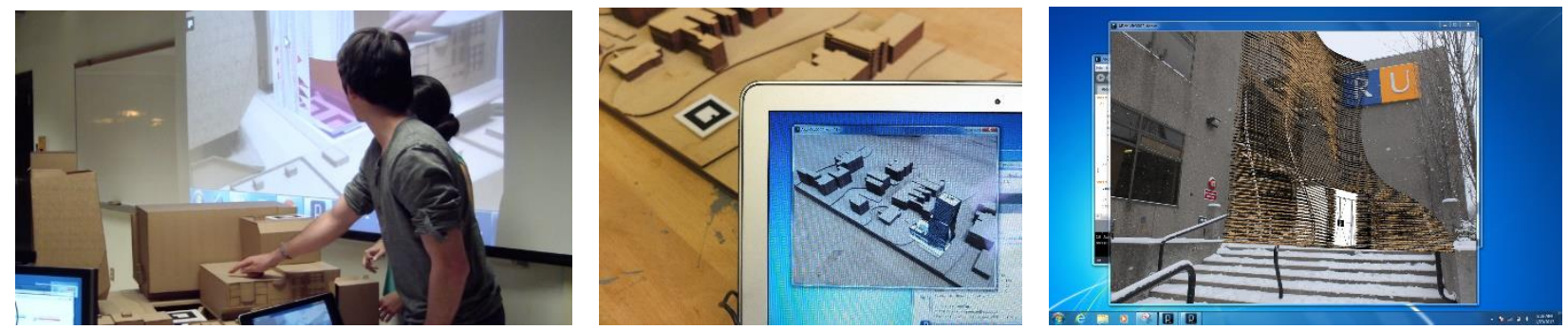

Fig. 3: ARIDD Project at Ryerson University, where glyphs are used to track the digital models placement in the physical, both in scaled down and full-scale representations (Hui, Compeau, Pu, \& Arabian, 2013).

Video-game engines have been adapted for architectural visualization, providing live feedback in spatial projection to changes in the digital model (Hui, Estrina, Huang, \& Algma, 2020). By increasing rendering efficiency and material mapping, various plug-ins and software including Enscape and Twinmotion, give suers the ability to navigate their digital models in a live VR environment (Hui, Estrina, Huang, \& Algma, 2020). At Ryerson University's Department of Architectural Science, students use these VR technologies not only to experience the spaces they design and gain insight from scale, material, and spatial aspects (Hui, Estrina, Lee, Zhou, \& Kinuthia, 2020) but also collaborate within that virtual environment, with student being able to make changes and experience them in VR instantaneously (Hui, Estrina, Huang, \& Algma, 2020).

A significant component of design studio is in the feedback students obtain, both from faculty and their peers. With the current model of online education, many of the reviews students receive are lacking, due to not only the absence of non-physical cues but also the interface and communication limitation they are confined to via virtual conferencing platforms. Spatial avatar-mediated conferencing applications, such as Spatial.io, offer an alternative platform for such conversations via either VR or MR headsets (Fig. 4). In these virtual spaces, students and faculty alike can not only place imagery and models for discussion, but also are able to interact with the content and even draw over it. In a 10-week study conducted by Akers, Zimmermann, Trutoiu, Schowengerdt, \& Kemelmacher-Shlizerma (2020), undergraduate students were asked to use the Spatial software to present their final materials, which varied in media including documents, videos, and 3D models. In a subsequent questionnaire, students stated they found their experience with the software was very positive, with many advantages over the typical 2D video conferencing, including a stronger sense of presence of their peers and instructors, ability to direct attention, improved means to share 3D content, and the ease of collaboration (Akers, Zimmermann, Trutoiu, Schowengerdt, \& KemelmacherShlizerma, 2020). These virtual meeting rooms are not limited to expensive headsets and can be accessed through mobile applications where they act as an MR overlay onto the user's surroundings, allowing students to use their mobile phones to access the virtual meeting rooms individually.
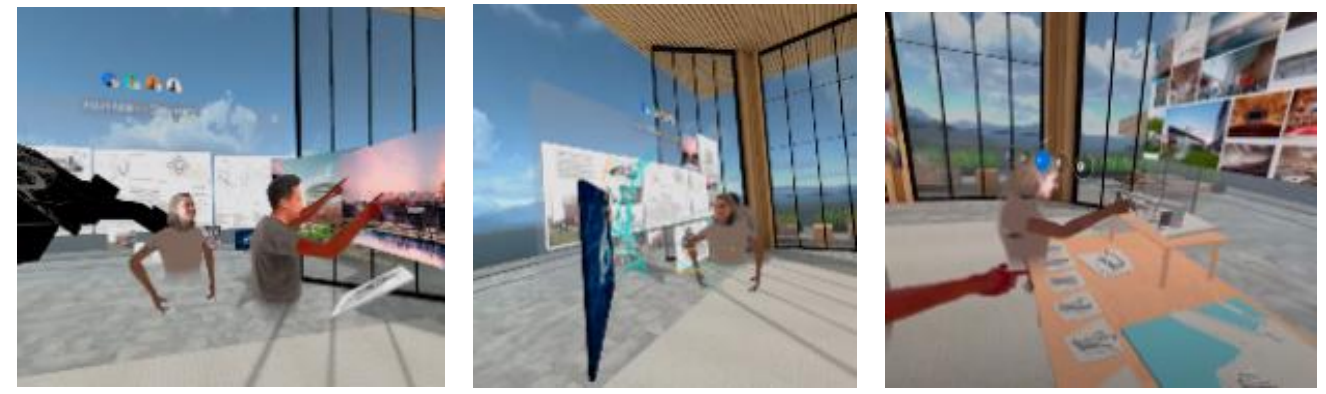

Fig. 4: Virtual Reality meetings in the software Spatial.io which allow multiple users to occupy the same virtual environment simultaneously.

\subsection{Extended Realities in Hands-On Experiential Learning Opportunities}

Outside of the design studio environment, extended reality technologies serve to incorporate experiential learning into architectural pedagogy. As architects are involved in many aspects of the AEC industry, and are frequently responsible for not only the conceptual design, but also the detailing, costing, fabrication, and the coordination of trades. As such, it is imperative for architecture students to not only have strong design and communication skills, but also understand construction and fabrication processes, material properties, and the ability to problem solve construction-related issues. As building construction processes are very costly, time consuming and require a lot of space, they are prohibitive for many architecture schools to embark on. Instead, students are able to use extended realities to transport themselves to construction sites, gain 
greater insight about the processes and trades, and even discover new material and construction methods.

It is invaluable for students to gain a greater understanding of construction processes, both by observing fabrication and by visiting construction sites. However, it is frequently difficult to arrange such opportunities for students directly. VR tours of in-progress construction can serve as a means for students to gain such experience, while MR overlays over sites can give students explanations and greater insight into the goings on when visiting in-progress construction. In addition, virtual training for trades could provide students with a more complete understanding of detailing and building assemblies, through participation, which has proved to be successful on construction sites (Ahmed, 2018).

Although computer aided design has given architects the ability to generate complex geometries in the virtual space, they have a very limited ability to participate in the fabrication, construction, and materialization of designs (Jahn, Newnham, van der Berg, Iraheta, \& Wells, 2019). Holographic tools have begun to be incorporated in various construction processes, aiding tradesmen to construct complex $3 \mathrm{D}$ geometries. MR head-mounted displays are used to present trade and craftsmen with holographic guides in the positioning, the forming, and the assembly of complex geometries by providing visual holographic representation of the end goal in front of the user. This technique is most effective in fabrication and construction situations where 2D drawings and physical templates are insufficient in translating exact geometries and 3D spatial representations are required for the design (Jahn, Newnham, van der Berg, Iraheta, \& Wells, 2019). This has begun to be used in several fields, most notably in the laying of complex brick layers (Jahn, Newnham, van der Berg, Iraheta, \& Wells, 2019). The augmentation of construction processes and the aiding the fabricator in the creation affords students the opportunity to not only have greater influence in the construction process but also get the opportunity to be involved as well. As extended realities have proven to be very effective for the quick and cost-effective, training of construction workers and tradesmen, architecture students are able to similarly be trained in rudimentary construction and fabrication techniques (Wang, Wu, Wang, Chi, \& Wang, 2018). Such knowledge gives architecture students a much more holistic understanding of construction methods and assemblies and would allow them to more effectively design, while also being able to conjecture more advanced solutions to construction-related problems.
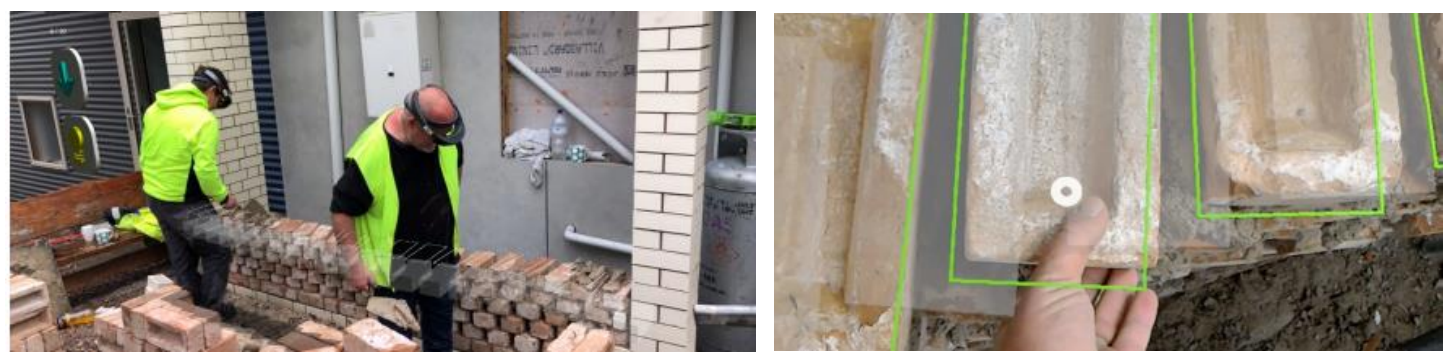

Fig. 9: MR used in brick laying in order to visualize the placement of a complex pattern and guide the trades in the construction (Jahn, Newnham, van der Berg, Iraheta, \& Wells, 2019).

By harnessing the visual instruction MR can provide throughout fabrication, this tool has been harnessed in not only the instruction of students in typical construction methods, but also in challenging students to experiment with materials, fabrication techniques, and begin to develop problem solving within construction contexts. In several courses instructed at UCL Bartlett B-Pro AD, students are encouraged to use innovative material experimentation in order to generate precise physical manifestations of their complex digitally generated geometries (Fig.10) (Hahm, Maciel, Sumitiomo, \& Lopez Rodriguez, 2019). Such fabrication methods gave students the ability to not only realize physically the very complex geometries they are able to model digitally, but also allowed them to become participants in the actual generation of the final product. While robotic and digital fabrication is frequently used when seeking precise formal accuracy, the combination of MR and human intuition eliminates the need for heavy computing and allows for a much more free and adaptive process (Hahm, Maciel, Sumitiomo, \& Lopez Rodriguez, 2019). In addition, expensive technologies like robotic arms and large-scale 3D printers are frequently prohibitively expensive to purchase and maintain within architecture institutions, making MR fabrications a much more cost-effective and flexible alternative. 

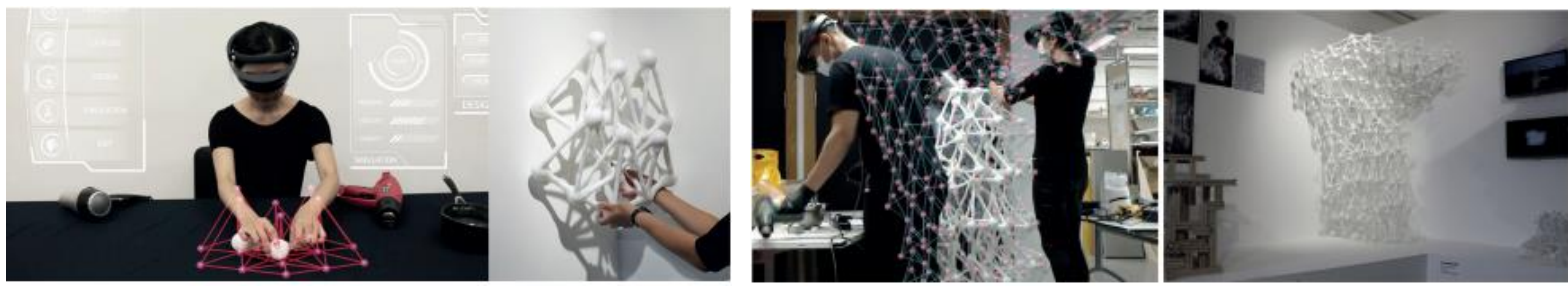

Fig. 10: Fabrication and material experimentation using MR technologies (Hahm, Maciel, Sumitiomo, \& Lopez Rodriguez, 2019).

Previous experimentation and research in fabrication a construction with MR culminated in educator and practitioner Soomeen Hahm to collaborate with Fologram to lead a team of students and researchers in the construction of the Steampunk Pavilion for the Tallin Biennale fabricated entirely through the use of MR (Fig. 11). This pavilion, composed of an aggregation of a multitude of variable steam-bent wood members, was erected entirely using MR, allowing for the replacement of typical drawings with 3D live visualization as guides for the students (Jahn, Wit and Samara 2019). By providing designers a constant visual representation of the desired condition, students were able to manipulate the wood members to very precise placements with little direction from 2D orthographic drawings, directly participating in the realization of their design work and having the opportunity to problem solve in a real-world setting.
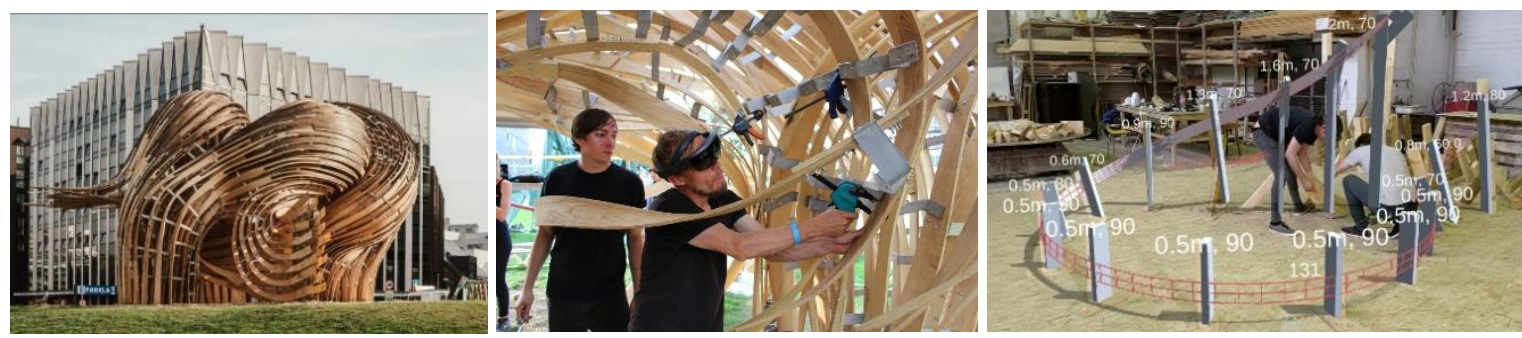

Fig. 11: Steampunk Pavilion by Soomeen Hahm Design and Fologram at the Tallinn Biennale, constructed by students using MR technologies (Pintos, 2019).

As construction and design-build projects are never individual endeavors, and are also products of student collaboration, MR technologies are able to be easily integrated into the collaborative fabrication workflow. While the procession of multiple MR headsets may not be feasible, the Holographic guides can be viewed from mobile devices as well allowing a large group of students to take part in the fabrication. In addition, the "shared goal conditions that define the bounds of free experimentation while ensuring that all participants work towards a known outcome" (Jahn, Newnham, \& van der Berg, Collaborative Fabrication In Mixed Reality, 2020). Using MR, human-robotic collaboration becomes possible as well. The interactivity of the MR medium can be leveraged in representation of unbuilt section of fabrication projects and allow for observers to manipulate outcomes of robotic processes (Betti, Aziz, \& Ron, 2019).

\section{CONCLUSION}

XRs have become an emerging representational tool giving students and instructors a platform to visualize architecture in interactive and immersive three-dimensional ways, opening new presentation, fabrication, instruction and design possibilities. Through the integration of a combination of tools ranging in accessibility and cost, educators are able to harness a multitude of possibilities of representation in the improvement of accessibility to content. Over the course of the remote education due to the COVID-19 pandemic (Silverman, Sibbald, \& Stranges, 2020) educators XRs provide opportunity to enhance communication, collaboration, and experiential learning within the online classroom. Future applications of XR technologies may involve telepresence-based human-robotic interaction (Duke, 2000), which would allow for full digital and physical globalization. XR technologies have begun to permeate throughout education for their usefulness in digital representation, and their role will surely grow as technologies develop and become more accessible to educators. 


\section{REFERENCE LIST}

Ahmed, S. (2018, November 5). A Review on Using Opportunities of Augmented Reality and Virtual Reality in Construction Project Management. Organization, Technology and Management in Construction, 10, 1839-1852.

Akers, J., Zimmermann, J., Trutoiu, L., Schowengerdt, B., \& Kemelmacher-Shlizerma, I. (2020). Mixed Reality Spatial Computing in a Remote Learning Classroom. Symposium on Spatial User Interaction (SUI '20) (pp. 1-3). New York, NY, USA: Association for Computing Machinery.

Betti, G., Aziz, S., \& Ron, G. (2019, Septmeber). Pop Up Factory : Collaborative Design in Mixed Reality. Simulation - VIRTUAL AND AUGMENTED REALITY 2, 3, 115-125.

Broll, W., Lindt, I., Ohlenburg, J., Wittkamper, M., Yuan, C., Novotny, T., . . Strothmann, A. (2004). ARTHUR: A Collaborative Augmented Environment for Architectural Design and Urban Planning. Journal of Virtual Reality and Broadcasting.

Carter, W. M. (2017, September 28). Virtual Archaeology \& Envisioning the Unseen Within the Archaeological Record. Retrieved from Western Graduate \& Post Doctoral Studies Electronic Thesis and Dissertation Repository: 2017

Dawkins, O., \& Young, G. (2020). Workshop-Ground Truthing and Virtual Field Trips. 2020 6th International Conference of the Immersive Learning Research Network (iLRN). San Luis Obispo, CA, USA: IEEE.

Duke, A. (2000). An Integrated Telepresence Environment for Collaboration in Construction. Engineering with Computers, 287-306.

Hahm, S., Maciel, A., Sumitiomo, E., \& Lopez Rodriguez, A. (2019). Flowmorph: Exploring the HumanMaterial Interaction in Digitally Augmented Craftsmanship. Intelligent \& Informed, Proceedings of the 24th International Conference of the Association for (pp. 553-562). Hong Kong: Association for Computer-Aided Architectural Design Research in Asia (CAADRIA).

Hui, V., Compeau, M., Pu, K., \& Arabian, T. (2013). Design in Hand | A Pedagogical Application of Augmented Reality in Design Development. 7th International Technology, Education and Development Conference Proceedings (pp. 5987-5996). Valencia, Spain: INTED 2013.

Hui, V., Compeau, M., Pu, K., \& Arabian, T. (2013). Eliminating Virtual Barriers | Augmented Reality in Architectural Design through Arch-Viz. 5th International Conference on Education and New Learning Technologies Proceedings (pp. 1137-1143). Barcelona, Spain: EDULEARN13.

Hui, V., Duldul, D., McCarthy, G., \& Ghantous, S. (2012). [AR]chiectural Education: Augmented Reality Tools in and out of the Classroom. 6th International Technology, Education and Development Conference Proceedings (pp. 2143-2151). Valencia, Spain: INTED 2012.

Hui, V., Estrina, T., Huang, A., \& Agma, S. (2020). Virtual Reality as a Response to Emergent Challanges in Architectural Education. ADVED. Istambul, Turkey.

Hui, V., Estrina, T., Lee, S., \& Sarmiento, K. (2019). Advanced Computer Visualization in Architectural Pedagogy. 12th annual International Conference of Education, Research and Innovation. Seville, Spain.

Hui, V., Estrina, T., Lee, S., Zhou, G., \& Kinuthia, V. (2020). Architectural Accessibility and Pedagogy via Virtual Reality Integraation. Proceedings from Hawaii University Conference on Arts, Humanities, Science and Education. Honolulu: Hawaii University ConferencesHawaii University Conferences.

Hui, V., Estrina, T., Zhou, G., \& Lee, S. (2020). Integrating Indigenous Archeology into Contemporary Architectural Pedagogy. HUIC AHSE Proceedings. Honolulu, Hawaii.

Hui, V., Townsend, S., Gantous, S., \& and McCarthy, G. (2013). Arch-App | An Application for Architectural Design Pedagogy. DesignEd Asia Conference Proceedings. Hong, Kong.

Ishii, H., Underkoffler, J., Chak, D., Piper, B., Ben-Joseph, E., Yeung, L., \& Kanji, Z. (2002). Augmented Urban Planning Workbench: Overlaying Drawings, Physical Models and Digital Simulation. Proceedings of IEEE \& ACM ISMAR 2002. IEEE.

Jahn, G., Newham, C., \& van der Berg, N. (2019). Making in Mixed Reality. Recalibration: On Imprecision and Infidelity. Mexico City. 
Jahn, G., Newnham, C., \& van der Berg, N. (2020). Collaborative Fabrication In Mixed Reality. In F. Melendez, N. Diniz, \& M. Del Signore, Data, Matter, Design (pp. 239-248). Routledge.

Jahn, G., Newnham, C., van der Berg, N., Iraheta, M., \& Wells, J. (2019). Holographic Construction. Design Modelling Symposium. Berlin.

Jahn, G., Wit, A., \& Samara, J. (2019). [BENT] Holographic handcraft in large-scale steam-bent timber structures. ACADIA 2019. Austin, Texas.

McVeigh-Schultz, J., Márquez Segura, E., Merrill, N., \& Ibister, K. (2018). What's It Mean to "Be Social" in VR?: Mapping the Social VR Design Ecology. DIS 2018, (pp. 289-94). Hong Kong.

Mead, C. B. (2019). Immersive, interactive virtual field trips promote science learning. Journal of Geoscience Education, 131-142.

Megahed, N. (2013). Augmented Reality Based-Learning Assistant for Architectural Education. International Journal on Advances in Education Research, 1(1), 35-50.

Milgram, P., \& Colquhoun, H. (1999). A Taxonomy of Real and Virtual World Display Integration. In Mix. Real. (pp. 1-26).

Nagakura, T., Mann, E., \& Keller, E. J. (2019). Telling Stories of Site: The Case of Lifta, Jerusalem. International Conference on Cultural Heritage and New Technologies. Vienna, Austria.

Ockman, J., \& Williamson, R. (2012). Architecture School Three Centuries of Educating Architects in North America. MIT Press.

Paavilainen, J., Korhonen, H., Alha, K., Stenros, J., Koskinen, A., \& Mayra, F. (2017). The Pokémon GO Experience: A Location-Based Augmented Reality Mobile Game Goes Mainstream. CHI '17: Proceedings of the $2017 \mathrm{CHI}$ Conference on Human Factors in Computing Systems, (pp. 24932498).

Pintos, P. (2019). Steampunk Pavilion / Gwyllim Jahn \& Cameron Newnham + Soomeen Hahm Design + Igor Pantic. Retrieved from ArchDaily: https://www.archdaily.com/926191/steampunk-paviliongwyllm-jahn-and-cameron-newnham-plus-soomeen-hahm-design-plus-igor-pantic

Rowen, I. (2020, May). The transformational festival as a subversive toolbox for a transformed tourism: lessons from Burning Man for a COVID-19 world. Tourism Geographies, 22(3), 1-8.

Silverman, M., SIbbald, R., \& Stranges, S. (2020). Ethics of COVID-19-related school closures. Canadian Journal of Public Health, 462-465.

Truth and Reconcilation Commission of Canada. (2015). Truth and Reconciliation Commission. Ottawa: Truth and Reconciliation Commission of Canada.

Wang, P., Wu, P., Wang, J., Chi, H.-L., \& Wang, X. (2018). A Critical Review of the Use of Virtual Reality in Construction Engineering Education and Training. International Journal of Envrionmental Research and Public Health, 15(1204).

Zarzycki, A. (n.d.). Teaching and Designing with Augmented Reality. CAAD Education. 1, pp. 357-64. eCAADe. 